\title{
Healthcare Management using ICT and IoT based 5G
}

\author{
Vijey Thayananthan \\ Department of Computer Science \\ King Abdulaziz University, Jeddah 21589, Saudi Arabia
}

\begin{abstract}
In healthcare management, all patients need to be looked after properly with the latest technology. Although treatment facilities of healthcare management are available wirelessly, many treatments are still pending and delayed because the number of patients is increasing. In this research, 2 problems are focused on they are the availability of treatment facilities and an efficient way of handling healthcare administration records. In healthcare management, e_Health applications focus on medical treatment and administration. However, these applications depend on the Information and Communication Technology (ICT) and Radio Frequency Identification (RFID) systems. Using IoT based 5G and the latest technologies, this research provides an efficient method to solve these problems. In this method, ICT based on $5 \mathrm{G}$ networks and IoT based 5G are the major components which include efficient management protocols for treating the patients and elders through the appropriate e_Health applications. Although some patients and older adults visit healthcare homes or hospitals regularly, they never become satisfied people because they always expect better services. Some healthcare management treats these people as customers and maintains customer relationship. Improving the accuracy and quality of healthcare services and customers' satisfaction depends on Customer Relationship Management (CRM) through evolving technologies. As results, ICT based on RFID and other latest technologies enhances the quality of e_Health application and healthcare services with the satisfaction of CRM values. Despite the profits and benefits, these enhancements are the conclusions of the healthcare service and management.
\end{abstract}

Keywords_Information communication technology; e_Health; customer relationship management; Radio Frequency Identification (RFID); Internet of Things based fifth generation (IoT based 5G)

\section{INTRODUCTION}

Healthcare industries are divided into two areas; they are such as private services are offered with the competition, and compulsory services are provided to everybody respectively. Even hospitals, which provide compulsory services are also becoming strategic organizations. Most of the hospitals in the world are privately owned because many different types of health issues are increasing with patients' population. These hospitals get profits through CRM values such as quality of service (QoS). Healthcare industries include hospitals, health care homes, elderly homes, etc.

In ICT based e_Health development, RFID was introduced to replace the barcode as the first issue in which CRM achieved first glance of enhancement successfully. The barcode replacement created satisfaction for both customers and organizations, where they gain the extra profit as well as timesaving in a number of ways such as quick changes in price, quick self-filling, etc. Barcode system is still used in many organizations, but RFID is going to move to the second generation of CRM enhancement, which investigates CRM values against future technologies. The features of ICT depend on the RFID and IoT devices which merge with the latest $5 \mathrm{G}$ based technologies.

In this research, healthcare industries are considered profitable organizations. With such organizations, CRM values are encouraged to increase the services as well as sell more medical products, gain more customers, lock the existing customers, and analyses the effectiveness of marketing activities. According to [1], the integration of IoT with 5G and RFID technologies provide a number of benefits in many potential applications such as e_Health, healthcare monitoring.

This research will focus on achieving appropriate CRM values through ICT for improving the quality of the e_Health services and applications. Overall objectives of the research are the improvement of the medical facilities such as efficient treatments on time with a less or manageable medical cost. Specifically, overall objectives focus on the enhancement of CRM through the RFID technologies which are being improved with next-generation technology and standard. With an improvement of CRM, all profitable and unprofitable organizations will achieve a better position of managing customers in all environments.

Although ICT is playing an important role in most of the administrations used in the e_Health applications, the roles of the social cognitive theory, satisfied connectivity, and perceived interactivity motivate us to investigate this research. Despite the RFID and ICT facilities in the e_Health applications, data collected from Facebook users. Here, ICT provides the social cognitive facilities to handle the health information between the users and health service providers. Authors claimed that their proposed model exchanged health information based on the social cognitive theory [2]. Further, their results motivate that human-to-human interaction with IoT, other interactions such as information handlings with human, outcome expectation of IoT based e_Health applications challenged with self-management competence, and outcome expectation of social relationships can be used to enhance the ICT facilities to improve the e_Health applications. Here, motivation is the development of intelligent ICT (IICT) which allows us to design and research new healthcare devices for managing the e_Health applications friendly manner influenced to improve the CRM values.

Although many challenges and possible implementations are urgent to improve the quality, I have focused on CRM values which allow health care providers to improve the safety issues such as medical errors, quick monitoring facilities of 
patients' identifications and efficient, caring services. The following contributions have been considered in this paper.

- Studying the existing healthcare issues depended on ICT, IoT, and RFID for managing the patients' healthcare system.

- Based on the study and investigation of current CRM values, management issues of e_Health applications such as patients' monitoring and caring services have been considered for improving the patients' healthcare services.

- Designing a model of generic CRM in healthcare using ICT, CRM values, IoT based $5 \mathrm{G}$ for improving the e_Health and healthcare management services.

- Finding the theoretical comparisons of CRM values for improving healthcare management such as QoS.

The rest of the paper is organized as follows. Section II focuses on the literature review and background. In Section III, we provide details of current technologies used in e-healthcare. Section IV explains the proposed model and brief methodology of the proposed scheme for e_Health based on CRM values. Theoretical analysis of the e_Healthcare services obtained from the selected CRM values for e_Health application is considered in Section V. In Section VI, overall conclusions are written based on the CRM values, theoretical analysis, and results.

\section{LITERATURE REVIEW AND BACKGROUND}

In general, healthcare information system (HIS) based on the RFID network and ICT management supports the Management Information System (MIS) and the Clinical Information System (CIS). To improve the HIS, the CRM values such as satisfaction should influence the administration and clinical requirements [3]. More and more healthcare organizations have started utilizing ICT with RFID to improve their CRM values [4]. Although HIS depends on this new utilization, some organizations face an error of at least 5 percent in their system. To overcome these errors, new organizations employ the IICT as a state of the art which not only increase the quality of e_Health applications and services but also minimize the medical cost.

Although RFID technology reduces the medical cost and offers tremendous benefits to the e_Health applications, employing RFID to analyze the CRM values in e_Health services will be one of the new challenges. Maximum security with minimum energy consumption can be considered through CRM values. Here, medical signal interferences and interactions are causing unnecessary problems such as insecure system during the medical operation when the RFID network is not configured correctly. In this situation, limitation and capacity of the RFID such as range of reader [5] (long or short range) should be employed according to the environment.

Psychological problems based on long-term diseases need some IICT based monitoring facilities. Here, the use of RFID and CRM values and e_Health services provided by IICT are also significant challenges. There will be plenty of other challenges related to long-term diseases such as diabetes because deceases will transform into new problems which never end. Table I shows the growth of CRM with evolving RFID technology [6] which improves the quality of life to all including patients who stay in the care homes and smart hospitals.

Everywhere, uses of IoT devices, smartphones, wearable tags, etc. increase the facilities of the e-healthcare services. Here, ICT enhances the management issues of e_Health applications such as handling patients' medical information or records. Although Fig. 1 shows the management issues, CRM values influence healthcare industries which provide the basic facilities to all patients. For instance, availability of healthcare service increases the satisfaction which improves the profit of the healthcare industries.

According to the healthcare industries, IoT provides many facilities such as quick feedback, adequate security, etc. which improve not only e_Health applications but also provide excellent services. Using IoT, patients feel the satisfaction with low-cost which is one of the CRM values. Integrating ICT with IoT enhances the healthcare monitoring facilities because RFID tags interact quickly with RFID readers merged with IoT devices. In mobile health, wearable IoT based tags and devices provide quick monitoring facilities which make happy feelings and satisfaction. When CRM values enhance the happy feelings through efficient technologies, e_Health applications based on CRM offer better services to patients and profits to healthcare industries.

According to [8-10], influences of IoT in RFID become identification of things (IDoT). This RFID enables e_Health devices to share their unique identification for monitoring the performance of available devices. IDoT technologies enhance the features of ICT when patients use e_Health applications. Further, IDoT allows healthcare providers to improve CRM values through availability, security, etc. With the growing era of IDoT, the communication between the medical devices which include patients' wearable tags, containers' tags, etc.

TABLE I. HealthCare Management with EVolving TeChNology

\begin{tabular}{|l|l|}
\hline Years & Evolving technology in healthcare \\
\hline Before 2010 & $\begin{array}{l}\text { First, 3 generations had been used with ICT and basic } \\
\text { barcode }\end{array}$ \\
\hline 2010 to 2011 & $\begin{array}{l}\text { The } 3^{\text {rd }} \text { generation had been dominating with the low- } \\
\text { cost RFID tags }\end{array}$ \\
\hline 2011 to 2020 & $\begin{array}{l}\text { With the 4G, e_Healthcare based on RFID, security, } \\
\text { IoT, and ICT is improving with CRM values }\end{array}$ \\
\hline After 2020 & $\begin{array}{l}\text { 5G will be dominating the healthcare services with } \\
\text { satisfaction, nursing, etc. based on RFID security and } \\
\text { privacy [7], ICT and IoT }\end{array}$ \\
\hline
\end{tabular}




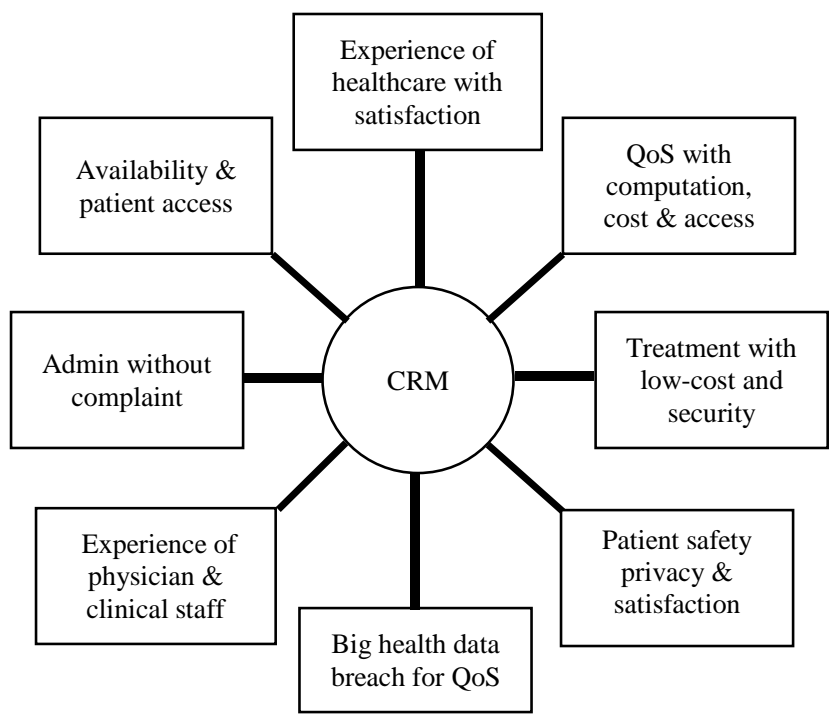

Fig. 1. Healthcare Management with CRM Values.

\section{CURRENT TeChNOLOGY IsSUES FOR HeAlthCARE}

Healthcare industries are merging with e_Health services and applications. Current technology issues are forcing to merge the e_Health services according to the patients' satisfaction which is one of the CRM values.

The potential e_Health applications have some influences with ICT and RFID for improving the patients' monitoring facilities in many directions [11]. All e_Health applications have to be invoked to treat the patients with their satisfaction which are CRM values [12-14] improve with the use of technologies. Satisfied patients considered as customers are loyal to their medical service providers which include the RFID-based HIS [15], hospitals, healthcare units, etc. Strategic approaches to using CRM values need some limitations according to the services used in the e_Health applications [16, 17]. The ICT implementation based on CRM values could enhance the medical services provided not only in the remote areas [18-22] but also in the war affected places.

According to the references [23, 24], authors have developed and analyzed the evaluating model for verifying the results of some selected e_Health applications. Through this conceptual model, e_Health applications based on ICT and CRM values have been considered to face some challenges [25]: they are remote monitoring in war-affected areas with low-cost RFID, climate changes, polluted air, etc.

\section{A. RFID in e_Health Applications}

The use of RFID in the medical system enhances not only the patients' monitoring facilities but also improve the services handled through modern technologies. Here, the authors have used the technology, organization, and environment (TOE) framework [26] to manage the medical care and systems. Despite many frameworks, shortages of medicine and medical systems were impeding the effort to control the e_Health applications such as diseases and administration of the medical care respectively. Hence, enabling or impeding RFID simplifies not only the healthcare asset management but also medical operations. Using TOE within healthcare management, healthcare providers improve their service through technology such as RFID, ICT, etc., an organization such as hospitals and environments such as remote areas. As far as the results of the TOE are concerned, RFID vendors and healthcare service providers enhanced the implications of the healthcare services and e_Health applications through using and implementing TOE framework. Authors claimed that RFID implementations enhanced the medical facilities using six different cases which include the CRM values indirectly. Table II provides examples of CRM values and ICT involvements in RFID applications.

Although healthcare provides the basic facilities to all patients and elders, CRM enhances healthcare services with maximum benefits. Thus, generic function (1) depends on many inputs to improve the benefits of healthcare.

TABLE II. IDOT APPLICATION BASED ON CRM

\begin{tabular}{|l|l|}
\hline $\begin{array}{l}\text { Examples of } \\
\text { CRM values }\end{array}$ & Healthcare management with 5G based ICT and IoT \\
\hline Satisfaction & $\begin{array}{l}\text { All ICT based services and IDoT based monitoring } \\
\text { facilities will be available for managing personal and } \\
\text { confidential medical data with satisfaction }\end{array}$ \\
\hline Cost & $\begin{array}{l}\text { Low-complex technology, quick treatments, and } \\
\text { responses without delay, secure system with IDoT, etc., } \\
\text { managing resources and services efficiently }\end{array}$ \\
\hline QoS & $\begin{array}{l}\text { Managing healthcare data without delay, leak, etc. } \\
\text { Regular healthcare with ICT \& IDoT, timekeeping, } \\
\text { maintaining maximum accuracy, etc. }\end{array}$ \\
\hline
\end{tabular}

$H=f($ Inputs to healthcare)

In (2), $\mathrm{H}$ is the healthcare function depended on the e_Health applications which involve with some healthcare inputs such as administration, treatments, CRM values, etc. This function may take $\mathrm{n}, \mathrm{m}$ and $\mathrm{r}$ inputs.

$H=\sum_{i=1}^{n} A_{i}+\sum_{j=1}^{m} T_{j}+\sum_{k=1}^{r} C_{k}$

Health is the service depended on quality, accuracy, etc. and the managing and maintaining a healthy life with the satisfaction and peaceful mind. Here, the administration of the health service should provide maximum satisfaction with lowcost.

\section{B. Healthcare with CRM}

Elderly people are struggling without proper management which influences with CRM values such as satisfaction, QoS, cost, etc. These days, satisfaction not only depending on the human admirations but also electronic tracking devices involved during the services offered by the elderly homes and hospitals [27, 28]. According to Innominato et al. [29], homebased e_Health multifunction and the multiuser platform provides maximum satisfaction when different e_Health applications are handled simultaneously. Daily data collected from the patients are sent to this platform for analyzing the patients' problems with their satisfaction. This platform allows the hospital team to handle the daily data with the efficient ICT concept from the specific server.

\section{Healthcare Management with Call Handling}

As an example scenario, the healthcare management with call handling can be improved using ICT concepts and latest 
technologies. As shown in Fig. 2, call handling provides many benefits to both users and service providers for improving CRM values.

In healthcare management, call handling dominates many issues to open the services between the users and medical service providers including nurses and physicians. Here, users may be patients, elders, others, etc. who expect to register for starting the healthcare services. Despite many online services, source and destinations are linked by wireless channels. Call handling initiates many issues, but some of the following issues in healthcare management are dominating the main medical services. They are the availability of the services, administration details for registrations, treatments strategies, etc.

Availability of service: All calls including online services interacted by users whenever they want. Here, QoS depends on the call handling (accepting, blocking, dropping, etc.).

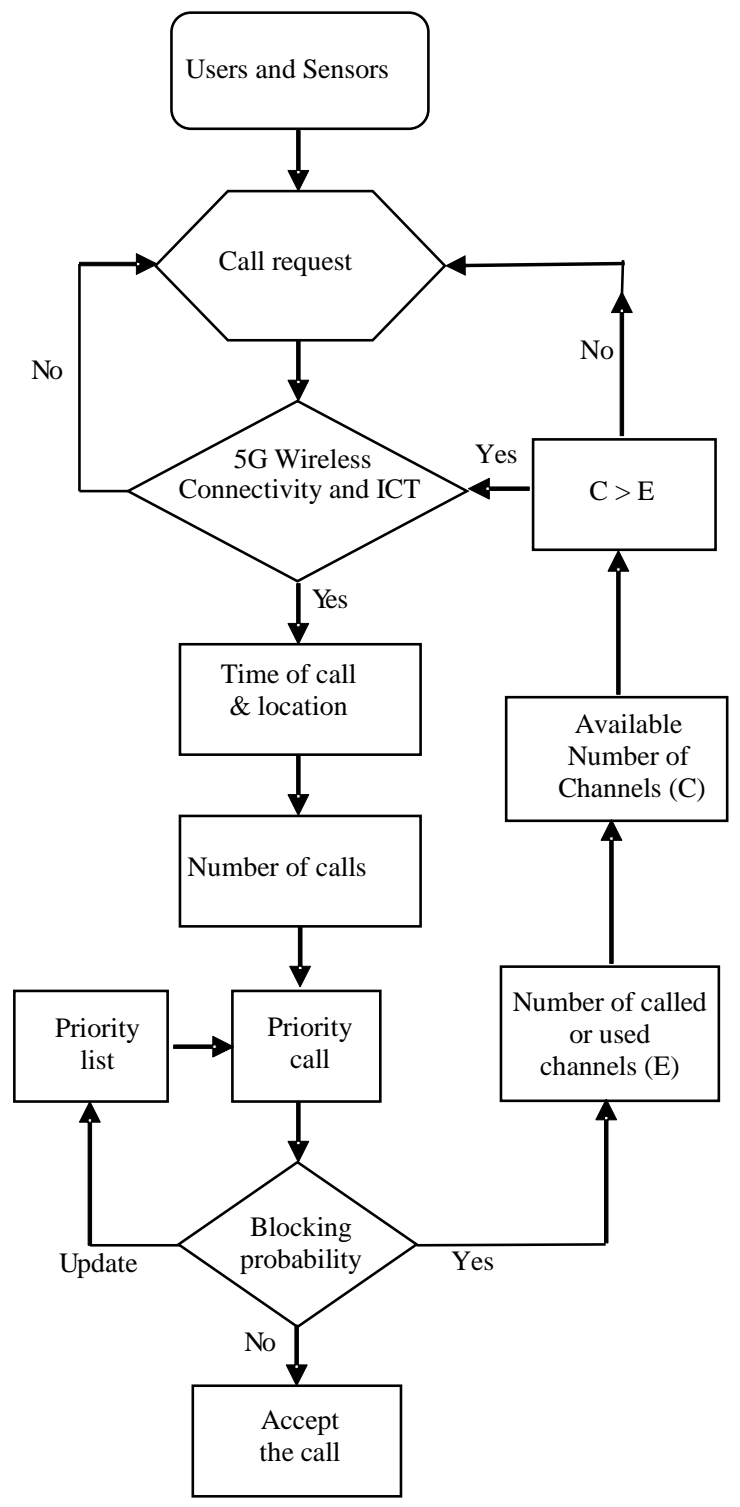

Fig. 2. Call Handling Scenario in Healthcare Management.
Administration details for registrations: All accepted calls should be registered without any data loss and delay influenced to QoS.

Treatment strategies: All registered calls should be allocated for caring or consulting with patients according to their priority and available resources. Here, minimum cost, maximum security, etc. are the key parameters of QoS.

In the call handling, the probability of priority calls can be calculated as $P=1 / e^{\mu t}$. Here, $\mu$ is the mean value of calls. When patia ent's random call $\mathrm{x}$ is active during the interval $\mathrm{t}$, the probability $\mathrm{p}$ is calculated to compute the expected number of channels and calls.

$P(x)=\frac{e^{-\lambda} \cdot \lambda^{x}}{x !}$

Where, $\lambda=\mu t$ represents the new online health enquiry rate. Although call handling represented by Poisson distribution (3), all priority and emergency calls can be considered for managing health services. Most of the CRM values depend on besthe $\mathrm{t}$ services used with time keeping, minimum delay, maximum security, etc. When service providers maintain the call handling accurately, QoS of the $\mathrm{CRM}$ value enhances the healthcare management.

\section{ICT for e_Health Applications}

The ICT system is being developed to integrate the health and social for collecting the CRM values which improve the e_Health applications. This integrated approach includes much more robust ICT solutions, along with new e_Health services that healthcare providers will also change the management behaviors. Several types of ICT tools developed to exchange health information (medical and administration) are identified in the e_Health applications. According to [30, 31], authors claimed that Integrated Care for Older Adults with Complex Health Needs (iCOACH) included the ICT facilities.

\section{PROPOSED MODEL}

Healthcare management depends on satisfaction, quality, experience, competition, etc. Here, the proposed model employs the generic CRM which enhances the healthcare facilities. The rationale for this model is that the needs of generic CRM can be effectively studied by understanding how CRM value is delivered to the customer (patients and elders). Also, this model shows how ICT based on IoT or 5G technology can be employed to deliver better healthcare such as QoS, cost, and satisfaction. The accuracy of the technologybased treatments can be considered as an overall quality which is given below:

$Q(\tau)=W_{T}+W_{D}+W_{J}+W_{C}$

Here, $\tau$ is the time dependent matrix for prioritizing the users' case and situations. To measure the quality, each weight is multiplied as $W_{T}=a_{T} \times w_{T}, W_{D}=a_{D} \times w_{D}, W_{J}=a_{J} \times w_{J}$, and $W_{C}=a_{C} \times w_{C}$. Where, best throughput $\left(a_{T}\right)$ minimum delay $\left(a_{D}\right)$, minimum jitter $\left(a_{J}\right)$ and quick and best charger $\left(a_{C}\right)$ are the independent parameters. In (4), $w_{T}, w_{D}, w_{J}$ and $w_{C}$ are weights of the throughput, delay, jitter and charging respectively. Strategically, this model is very useful for the CRM process. It attempts to provide a rationale for applying 
RFID technology in the healthcare industries, and it also serves as a healthcare manager for monitoring e_Health applications.

As shown in Fig. 3, a proposed model based on a generic CRM approach can be developed to improve the healthcare service which depends on the quality [33, 34]. Healthcare technology changes are improving daily. Therefore, healthcare industries update their facilities with reasonable changes, which will affect all issues in the business including CRM. Through this model, organizations can identify the opportunities and develop e_Health strategies, payment policies [35], etc. With an appropriate CRM policy, healthcare services can be created and implemented for improving healthcare management. The CRM policies depend on CRM values attracted to the customer (patients or older adults). Despite many CRM values and their updated issues such as technical requirements and policies, patients need quick, lowcost and peaceful service according to e_Health applications. Updating the policies of CRM values enhances the profit and benefits of the healthcare industries. In this research, the role of ICT in the patients' care facilities is important to update the CRM policies. In addition, all CRM values including QoS not only depend on the users' of ICT infrastructure but also available best service of ICT merging with evolving technologies and policies.

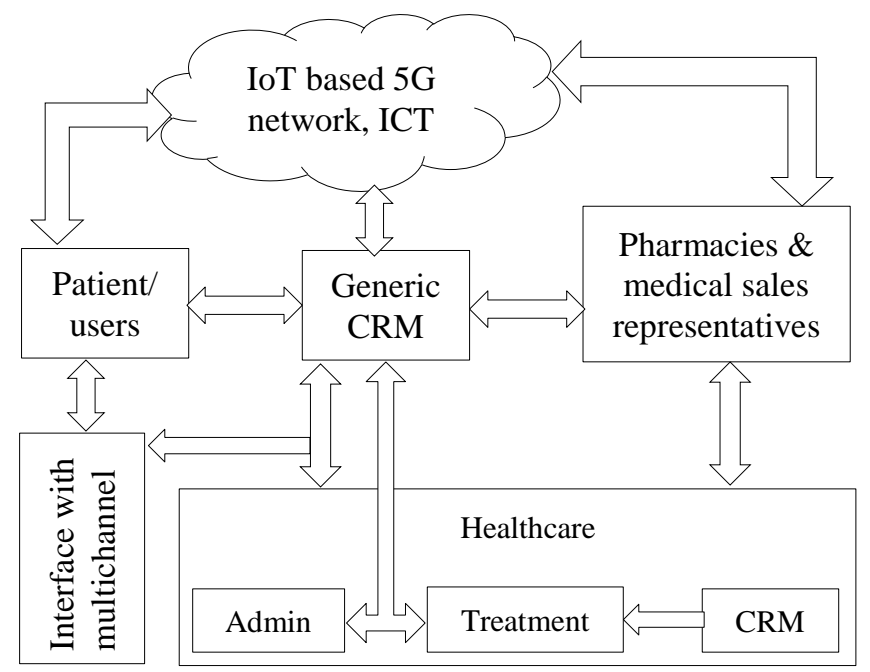

Fig. 3. A Proposed Model of Generic CRM in Healthcare.

Minimizing the medical cost is the ultimate target of all ordinary patients. All CRM values not only improve the overall performance of healthcare management but also provide support to all types of users. Service providers should maintain accuracy when they deploy the latest technologies. Accuracy keeps the satisfying treatment which creates satisfaction when patients use the e_Health applications.

\section{ANALYSIS AND DISCUSSIONS}

This section describes healthcare services and management prioritized as a QoS which provides the patients' satisfaction. Although healthcare management deals with many issues and services, handling calls and prioritizing calls according to the patients' health condition are considered as QoS.

\section{A. Operational Scenarios and Indicative Results}

New healthcare management will have some new resolutions based on the emerging technology of ICT and CRM values. The ICT based CRM policies will help to increase the quality of the healthcare services and industries' benefits (error reduction, quick monitoring, security, etc.). Following scenarios illustrate the CRM values when patients use basic ICT and IoT based ICT. In these scenarios, four types of healthcare and 100 patients are used for recording the patients' opinion of CRM values.

1) Scenario 1 (Cost with healthcare issues): Future of the e_Health services must be error free because still at least 5\% error causes many problems in healthcare industries. Fig. 4 shows the average cost of conventional and proposed ICT deployments with the increasing number of patients (users). In this analysis, the percentage of ICT-5G based IoT improves when users are increased. Hence, CRM value (cost) will be better when cost is considered as healthcare measurement during the call handling and patient monitoring. Cost related to a data breach can be reduced when healthcare units or industries provide better services and treatment with new technology.

Although accuracy calculations are dominating to reach the best service, healthcare management allows the service providers to maintain the accuracy for improving the patients' satisfaction.

2) Scenario 2 (QoS during the treatment): Future of the health care services and management will depend on the quick and efficient treatment facilities which maximize the health services and improve the overall quality and profit. Fig. 5 is an expected performance of quality issues during the healthcare services provided by hospitals and healthcare industries. When healthcare service providers increase their services and features involved with latest technologies such as IoT, IDoT, IoT based on 5G, etc., QoS increases. Also, technological issues such as $5 \mathrm{G}$ requirements (latency, delay, etc.) increase the QoS. With basic accuracy calculations, service providers can choose the best technology for maintaining healthcare applications. Also implementing IoT based 5G for improving ICT and healthrelated communication technologies such as call handling depending on the technical requirements. In e_Health application over the wireless communication, accuracy of the treatment is the most important parameter. It not only provides the accuracy of the medical treatment but also increases the QoS. Although medical services are leading to reach high quality and reputation, competition is still challenging with the evolving technology.

Technology is changing, merging and evolving with many new requirements but the percentage of QoS should increase with the implementation according to the service architecture of the $5 \mathrm{G}$ environments. 


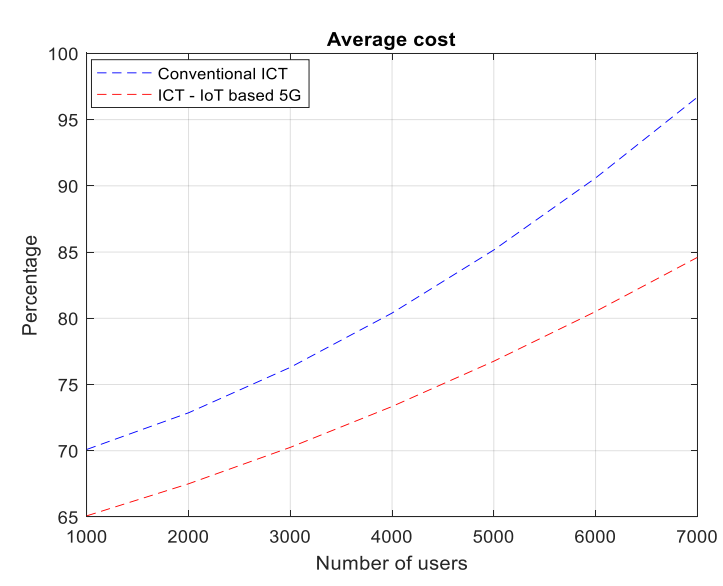

Fig. 4. Cost Improvement through ICT Technologies.

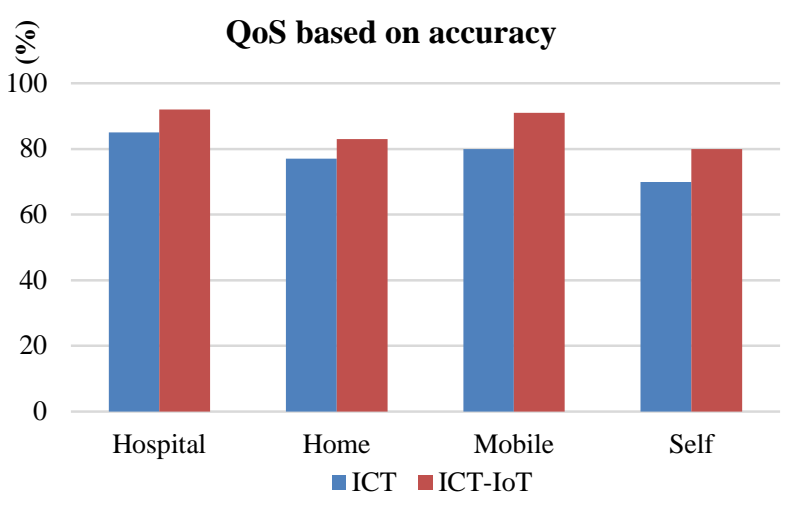

Fig. 5. Comparison of Technology Issues for Improving QoS.

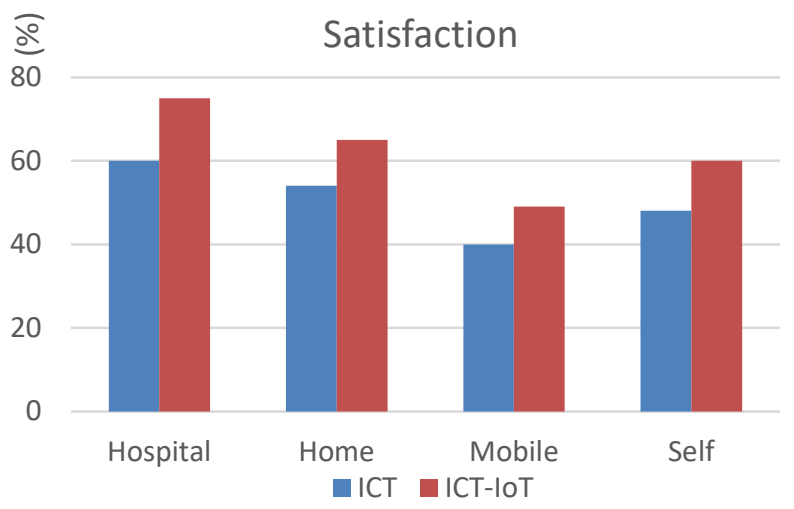

Fig. 6. Comparison of the Best Technology for Improving Satisfaction.

3) Scenario 3 (Satisfaction considered as best service): All medical services must be efficient with the nursing, caring, etc. which provide satisfaction. Regarding medical services, both patients and service providers should satisfy. Patients' satisfaction depended on the best service used through the best technology increase the CRM value of satisfaction as in Fig. 6. Future of healthcare management will be competitive with the best services, low-cost technology, and maximum satisfaction.
Through this research, at least a 10\% improvement in e_Health applications over the wireless network will be expected. Not only patients will enjoy the CRM values, but also customers (elders) who use the healthcare industries for their private purposes will enjoy the CRM values with the best and latest technology. Here, patients are like customers because patients not only use health care services but also they buy healthcare products regularly according to the e_Health applications and become happy and satisfied customers.

According to the properties of IoT devices, communication and computation capabilities are limited because IoT devices are very small and work with the low-power. Examples of IoT devices are wearable watches, smart cameras, etc. In CRM, IoT based devices help to improve the quality, accuracy, etc. which provides the satisfaction considered as one of the CRM values. For instance, wearable watches provide quick monitoring of health issues such as sugar levels of blood. This facility reduces the cost and time of the patient and increases the quality which improves the CRM values.

Although many securities are available for protecting data in public and private healthcare organizations, data breaching is damaging the accuracy and quality of the treatment. Currently, 5G provides efficient protection techniques for protecting data breaches. They are secure software-defined networks (SDN) with lightweight cryptographic algorithms; secure SDN based intelligent approach with routing algorithms, non-orthogonal multiple accessing techniques with physical layer security, etc.

Regarding the proposed model, cost and time are the important factors considered in figures $7 \mathrm{a}$ and $7 \mathrm{~b}$. Using this model, technology not only improves the e_Health applications and healthcare services but also cost ad time which involves with the CRM values. Table III illustrates the admin (call handling) and small treatments considered for measuring satisfaction ratio which increases with evolving technologies.
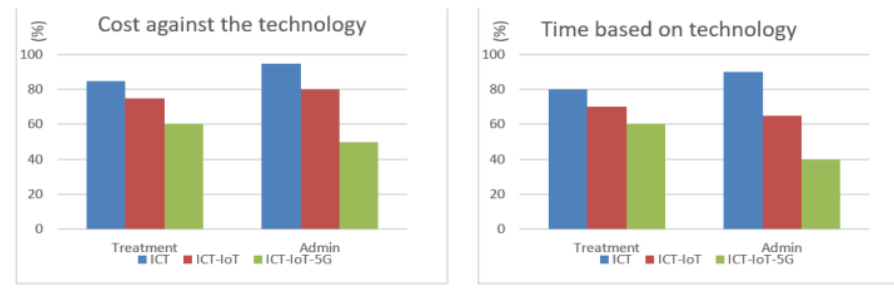

Fig. 7. Expected Improvements a) Cost and b) Time with Technologies.

TABLE III. SATisfaction RATiO Against The TEChNOLOGY

\begin{tabular}{|l|l|l|}
\hline \multirow{2}{*}{ Technology } & \multicolumn{2}{|l|}{ 0< Satisfaction ratio < 1 } \\
\cline { 2 - 3 } & $\begin{array}{l}\text { Call handling rate per } \\
\text { minute }(50 \text { calls })\end{array}$ & $\begin{array}{l}\text { Treatment per hour } \\
\text { (10 treatments) }\end{array}$ \\
\hline ICT & 0.4 to 0.5 & 0.45 to 0.55 \\
\hline ICT - IoT & 0.5 to 0.6 & 0.55 to 0.65 \\
\hline ICT IoT - 5G & 0.6 to 0.65 & 0.65 to 0.7 \\
\hline
\end{tabular}


Although many limitations in the healthcare management issues, limitation of this study focuses on QoS during the healthcare services, cost against healthcare services and profit through the CRM values. Healthcare facilities are improved by efficient services, secure technologies, minimum waiting time, etc. Using technology will not only improve profit and CRM values but also reduce the waiting time. When service providers consider all these limitations correctly according to the priority, both users and service providers will get the benefits. According to my opinion, these limitations will open many new research ideas and activities in this field. They are such as minimum waiting time and cost against the QoS, efficient use of technology and services against the cost, etc.

\section{B. Recent Advances in e_Health Systems}

Implementation of ICT and IICT should be available within the e_Health system for analyzing all healthcare services influenced by the patients' satisfaction. Here, the recent advance approach is CRM which depends on the ways patents are treated in the hospitals and healthcare units. In this approach, applying CRM values excellently within the healthcare system is one of the recent advances. Following technology, services, application, and facilities are examples of recent improvements in the e_Health system.

According to Newman-Casey et al. [36], experiences with e_Health technology among glaucoma patients and their relationship with medication adherence can be analyzed using CRM values which not only improve the e_Health applications but also simplify the patients' relationships when health providers set and apply medication adherence during the health monitoring and physical observations.

A systematic review of the technology acceptance model (TAM) [37] in health informatics, improve the e_Health services. Furthers, authors have identified three ICT application areas for implementing TAM in the healthcare services they are telemedicine, electronic health records, and mobile applications respectively. The ICT application area recently investigated using the TAM will be the major challenge for enhancing the healthcare facilities when e_Health applications are integrated with ICT. In addition to this, TAM can be extended to develop dynamic health service environments by the integration of components from CRM values. As discussed in [38], the ICT helps trauma survivors to improve their mental health services considered as e_Health applications. Here, existing treatments and patients' monitoring facilities which support the mental health services can be enhanced with the modern electronic technologies. Further, discussion allows researchers to understand how IICT or different technologies can be used for implementing therapeutic tasks with CRM values. Despite many treatments, trauma survivors need therapeutic processing which not only helps to remove mental disorders and problems but provides satisfaction. Intelligent approaches are minimizing the cost and time through the CRM values and technology enhances the flexibility of available services and capacity for decision making. Here, IICT allows healthcare users and service providers to manage their healthcare devices intelligently. Knowledge management (KM) in long-term care will allow healthcare service providers to set the barriers of health care such as users' knowledge. Furthermore, the authors proposed long-term care in a TOE framework with KM [32] and IICT concept. Although the framework includes security, complexity, and costs analysis mechanism, it provides CRM concepts to improve management support, nursing leadership, etc. According to [39], the ICT within the health system encourages the citizens which include service providers and users to improve their e_Health facilities. Authors prefer to deploy the ICT because citizens will get not only quick treatment but also they can have an efficient system with a less medical cost. Although the objective of this article is to manage the clinical products within the hospital or medical unit, important of the ICT facilities are considered. In this management, using CRM values will increase healthcare efficiency and economic efficiency.

\section{CONCLUSIONS}

The study of CRM values allows healthcare providers to improve the facilities of e_Health applications. Enhancement of the e_Health applications such as quality always increases the profit and benefits when healthcare users and service providers deploy the ICT, RFID, and IoT within the medical systems efficiently. In order to enhance the quality of healthcare and e_Health development using ICT, CRM values and $5 \mathrm{G}$ based IoT, the efficient proposed model is introduced in this paper. The CRM values and applications of RFID and IoT enhance the healthcare facilities through the ICT which works with the latest technologies and provides user-friendly features to e_Health users. Also, ICT-5G based IoT technology improve the average healthcare cost. Satisfaction and other CRM values such as QoS depend on the accuracy of the treatments involved with the technology.

Future work is to find low-cost solutions which minimize the overall cost of the medical cost and waiting time through the QoS as CRM value, ICT, RFID, modern technologies, etc. All over the world, the evolution of technology is increasing in many dimensions but the cost and waiting time in hospitals are increasing without proper management. The services with CRM values should be implemented in all actions of the hospital or medical services satisfied by moral and ethical issues. These are the only valuable key terms derived from the CRM values. The objectives of the e_Health application are low-cost medical facilities, minimum waiting time, etc. But, high medical cost and intolerable waiting time are creating low-quality services rather than the best services with maximum moral issues. ICT provides many benefits to users and service providers for delivering efficient services. Further, it simplifies business communication through the available technical capabilities.

\section{ACKNOWLEDGMENT}

This work was funded by the Deanship of Scientific Research (DSR), King Abdulaziz University, Jeddah, under grant No. (D1435-362-611). The authors, therefore, acknowledge with thanks, DSR technical and financial support.

\section{REFERENCES}

[1] Sharif, Abubakar, Jun Ouyang, Feng Yang, Hassan T. Chattha, Muhammad Ali Imran, Akram Alomainy, and Qammer H. Abbasi. "Low-cost, Inkjet-printed UHF RFID Tag based System for the Internet of Things Applications using Characteristic Modes." IEEE Internet of Things Journal (2019). 
[2] Lin, Hsien-Cheng, and Chun-Ming Chang. "What motivates health information exchange in social media? The roles of the social cognitive theory and perceived interactivity." Information \& Management 55, no. 6 (2018): 771-780.

[3] Alzahrani A, Qureshi MS, Thayananthan V. RFID of next-generation network for enhancing customer relationship management in healthcare industries. Technology and Health Care. 2017 Jan 1;25(5):903-16.

[4] Thayananthan V, Alzahrani A, Qureshi MS. Information and communication technology (ICT) applications for customer relationship management (CRM). InICTs and the Millennium Development Goals 2014 (pp. 161-183). Springer, Boston, MA.

[5] Nordby K. Conceptual designing and technology: Short-range RFID as a design material. International Journal of Design. 2010;4(1):29-44.

[6] Tsai, Meng-Hsiun, Chiu-Shu Pan, Chi-Wei Wang, Jui-Ming Chen, and Cheng-Bang Kuo. "RFID Medical Equipment Tracking System Based on a Location-Based Service Technique." Journal of Medical and Biological Engineering 39, no. 1 (2019): 163-169.

[7] Juels A. RFID security and privacy: A research survey. IEEE Journal on selected areas in communications. $2006 \mathrm{Feb}$;24(2):381-94.

[8] Chen, Yen-Hung, Rui-Ze Hung, Lin-Kung Chen, Pi-Tzong Jan, and Yin-Rung Su. "Channel-Quality Aware RFID Tag Identification Algorithm to Accommodate the Varying Channel Quality of IoT Environment." Applied Sciences 9, no. 2 (2019): 321.

[9] Amendola, Sara, Rossella Lodato, Sabina Manzari, Cecilia Occhiuzzi, and Gaetano Marrocco. "RFID technology for IoT-based personal healthcare in smart spaces." IEEE Internet of things journal 1, no. 2 (2014): 144-152.

[10] Ciftler, Bekir Sait, Abdullah Kadri, and Ismail Güvenç. "IoT localization for bistatic passive UHF RFID systems with 3-D radiation pattern." IEEE Internet of Things Journal 4, no. 4 (2017): 905-916.

[11] Wang SW, Chen WH, Ong CS, Liu L, Chuang YW. RFID application in hospitals: a case study on a demonstration RFID project in a Taiwan hospital. Innull 2006 Jan 4 (p. 184a). IEEE, pp. 1-10.

[12] V Wangenheim F. Situational characteristics as moderators of the satisfaction-loyalty link: an investigation in a business-to-business context. Journal of Consumer Satisfaction, Dissatisfaction, and Complaining Behavior. 2003 Jan 1;16, pp. 145-156.

[13] Weng TS. Using information technology on customer relationship management. InWSEAS International Conference. Proceedings. Recent Adv. in Comp. Engineering 2009 Mar 23 (No. 10). WSEAS, pp. 271-79.

[14] Guha S, Harrigan P, Soutar G. Linking social media to customer relationship management (CRM): a qualitative study on SMEs. Journal of Small Business \& Entrepreneurship. 2018 May 4;30(3):193-214.

[15] Wu CH, Ip WH, Kwok SK, Ho GT, Chan CY. Design and Development of an RFID-based HIS-A Case Study. International journal of engineering business management. $2011 \mathrm{Feb}$ 15;3(1.):1-8.

[16] Leema AA, Hemalatha M. Applying RFID Technology to construct an Elegant Hospital Environment. International Journal of Computer Science Issues (IJCSI). 2011 May 1;8(3):444.

[17] Yao W, Chu CH, Li Z. The use of RFID in healthcare: Benefits and barriers. InRFID-Technology and Applications (RFID-TA), 2010 IEEE International Conference on 2010 Jun 17 (pp. 128-134). IEEE.

[18] Tariq A, Tanwani A, Farooq M. User-centered design of e-health applications for remote patient management. The in10th annual conference of the NZ ACM special interest group on human-computer interaction, CHINZ 2009, Auckland, NZ 2009.

[19] Tzeng SF, Chen WH, Pai FY. Evaluating the business value of RFID: Evidence from five case studies. International journal of production economics. 2008 Apr 1;112(2):601-13.

[20] Wu NC, Nystrom MA, Lin TR, Yu HC. Challenges to global RFID adoption. InTechnology Management for the Global Future, 2006. PICMET 20062006 Jul (Vol. 2, pp. 618-623). IEEE.

[21] Roussos G. Networked RFID: systems, software, and services. Springer Science \& Business Media; 2008 Oct 17.

[22] Ngai EW, Suk FF, Ng CC. An information system design theory for an RFID-based healthcare management system. PACIS 2008 Proceedings. 2008 Jul 3:178.
[23] Yang S, Zhang R, Liu Z. The AGA is evaluating a model of customer loyalty based on the e-commerce environment. Journal of Software. 2009 May;4(3):262-269.

[24] Cohen TN, Cabrera JS, Litzinger TL, Captain KA, Fabian MA, Miles SG, Reeves ST, Shappell SA, Boquet AJ. Proactive safety management in trauma care: applying the Human Factors Analysis and Classification System. Journal for Healthcare Quality. 2018 Mar 1;40(2):89-96.

[25] Inaba, T. "Realization of SCM and CRM by using RFID-captured consumer behavior information." Journal of Networks. 2009 no. 2: 92-9.

[26] Aboelmaged M, Hashem G. RFID application in patient and medical asset operations management: A technology, organizational and environmental (TOE) perspective into key enablers and impediments. International journal of medical informatics. 2018 Oct 1;118:58-64.

[27] Ruan W, Sheng QZ, Yao L, Li X, Falkner NJ, Yang L. Device-free human localization and tracking with UHF passive RFID tags: A datadriven approach. Journal of Network and Computer Applications. 2018 Feb 15;104:78-96.

[28] Cerlinca TI, Turcu C, Turcu C, Cerlinca M. RFID-based information system for patients and medical staff identification and tracking. InSustainable Radio Frequency Identification Solutions 2010. InTech.

[29] Innominato P, Komarzynski S, Karaboué A, Ulusakarya A, Bouchahda M, Haydar M, Bossevot-Desmaris R, Mocquery M, Plessis V, Lévi F. Home-based e-health platform for multidimensional telemonitoring of symptoms, body weight, sleep, and circadian activity: relevance for chronomodulated administration of irinotecan, fluorouracil-leucovorin, and oxaliplatin at home-results from a pilot study. JCO Clinical Cancer Informatics. 2018 Feb 22;2:1-5.

[30] Gray CS, Barnsley J, Gagnon D, Belzile L, Kenealy T, Shaw J, Sheridan $\mathrm{N}, \mathrm{Nji}$ PW, Wodchis WP. Using information communication technology in models of integrated community-based primary health care: learning from the iCOACH case studies. Implementation of Science. 2018 Dec;13(1):87.

[31] Fernández ÒS, Pérez CG, García-Cuyàs F, Giménez NA, Gallego MB, Font AG, Quintana MG, Corbacho SH, Casellas ES. Shared Medical Record, Personal Health Folder and Health and Social Integrated Care in Catalonia: ICT Services for Integrated Care. InNew Perspectives in Medical Records 2017 (pp. 49-64). Springer, Cham.

[32] Donovan J, Franzel S, Cunha M, Gyau A, Mithöfer D. Guides for value chain development: a comparative review. Journal of Agribusiness in Developing and Emerging Economies. 2015 May 18;5(1):2-3.

[33] Mitchell J, Coles C, Keane J. Upgrading along value chains: strategies for poverty reduction in Latin America. COPLA Global-Overseas Development Institute, London. 2009 Dec.

[34] Carlson JJ, Sullivan SD, Garrison LP, Neumann PJ, Veenstra DL. Linking payment to health outcomes: a taxonomy and examination of performance-based reimbursement schemes between healthcare payers and manufacturers. Health policy. 2010 Aug 1;96(3):179-90.

[35] Newman-Casey PA, Killeen OJ, Renner M, Robin AL, Lee P, Heisler M. Access to and Experiences with e-Health Technology Among Glaucoma Patients and Their Relationship with Medication Adherence. Telemedicine and e-Health. 2018 Apr 23.

[36] Rahimi B, Nadri H, Afshar HL, Timpka T. A Systematic Review of the Technology Acceptance Model in Health Informatics. Applied clinical informatics. 2018 Jul;9(03):604-34.

[37] Azarang A, Pakyurek M, Giroux C, Nordahl TE, Yellowlees P. Information Technologies: An Augmentation to Post-Traumatic Stress Disorder Treatment Among Trauma Survivors. Telemedicine and eHealth. 2018 Jul 13.

[38] Lo MF, Ng PM. Knowledge Management for Health Care and LongTerm Care in the Technology-Organization-Environment Context. InSustainable Health and Long-Term Care Solutions for an Aging Population 2018 (pp. 161-186). IGI Global.

[39] Canha M, Marques CG, Loureiro R. The use of information and communication technologies in the management of clinical products. The Implementation of Advanced Warehouses in a Portuguese hospital center. Superavit. 2018 Apr 6;3:103-12. 